\title{
'TIME IS NOT A RIVER' \\ THE IMPLICATIONS OF MUMBO JUMBO'S PENDULUM CHRONOLOGY FOR COALITION POLITICS
}

\section{Tamiko Fiona Nimura University of Washington}

Ismael Reed's 1972 novel, Mumbo Jumbo, proposes a unique chronological theory that requires a multiplegrounded understanding of time. An analysis of what could be called this "pendulum" chronology leads to a more complete understanding of the novel and has important implications for a coalition of American ethnic studies and other identity-related work in the academy.

Arna Bontemps was correct in his new introduction to Black Thunder. Time is a pendulum. Not a river. More akin to what goes around comes around. (Locomobile rear moving toward neoned Manhattan skyline. Skyscrapers gleam like magic trees. Freeze frame.)

Jan. 31 st, 1971

3:00 PM

Berkeley, California Ishmael Reed, Mumbo Jumbo'

To begin at the end of Ishmael Reed's novel Mumbo Jumbo (1972) is entirely appropriate for a discussion of its chronology. The novel's final lines, quoted above, seem to leave us with a puzzling collage: part musings, part clichés, part screenplay, part 


\section{Ethnic Studies Review Volume 26: 1}

logistics. Here Mumbo Jumbo's main character, PaPa LaBas, muses: "Time is a pendulum. Not a river." 2 A few lines later Reed draws attention to the novel's completion, naming its specific date, time and place: "January 31st, 1971. 3:00 PM. Berkeley, California." 3 Following this pronouncement, such detailed attention to the novel's completion shows Reed's preoccupation with chronology: a struggle not only with monolithic narratives of history but also with an understanding of unidirectional time itself.

Though literary critics have considered Mumbo Jumbo's sense of history, few have developed an extended reading of its chronology or the implications of this chronology. Theodore O. Mason characterizes Reed's view of history as "cyclical, yet simultaneously linear." 4 I would broaden Mason's characterization from "history" to "chronology," allowing for fictional as well as non-fictional events. Following the binary logic of poststructuralism, Henry Louis Gates, Jr. posits one "story of the past" and one "story of the present." Gates contends that the novel's structure is dualistic: it "[draws] upon the story of the past to reflect upon, analyze, and philosophize about the story of the present."5

In this paper I extend Gates' characterization of Mumbo Jumbo by suggesting that the novel draws on the story of several pasts, both to reflect upon the story of the novel's multiple "presents" and to prophesy about the future. And indeed in a 1974 interview Reed remarked that this was one of his main purposes in writing the novel: "I wanted to write about a time like the present, or to use the past to prophesy about the future-a process that our ancestors called 'Necromancy.' I chose the 20s because [that period was] very similar to what's happening [in the late 1960s/early 1970s]."6 The novel's final lines ground Mumbo Jumbo in several time periods, including the 1920s Harlem Renaissance and the early 1970 s. The chronology represented in these lines might appear to be another confusing aspect of an already confusing novel. How are we to understand time as a "pendulum" while paying static attention to one time period (1971)? And what will such simultaneous grounding do for our understandings of the novel? To answer these questions we must read the novel according to its own chronological theory.

I argue here that Mumbo Jumbo proposes its own chronological theory; it argues for a multiply grounded understanding 
of time and for a long-term understanding of coalition. Reed's novel draws parallels between earlier and contemporary multiracial coalitions, shifting our sense of coalition from a one-way, linear process with a desired end product to a continually dialectical process. Examining several examples in the text will allow us to excavate Mumbo Jumbo's chronology and to identify the broader implications of that chronology not only for an understanding of the novel but also for coalitions of American ethnic studies and other identity-related work in the academy.

\section{Mumbo Jumbo's “Pendulum Chronology”}

Mumbo Jumbo is an intertextual collage, full of photographs and illustrations, diagrams, excerpts of dance manuals, letters, newsflashes, Time-Life history books, and even a partial bibliography. It is a satire, a detective novel, ${ }^{7}$ ostensibly set in the Harlem Renaissance, about the appearance of a plague, or an "anti-plague," "Jes' Grew." 8 Jes' Grew is an anti-plague because it is an "enlivening" plague, one that causes its carriers to be emotionally moved and to dance. Though Reed specifically mentions "Jes' Grew carriers" like Louis Armstrong and Charlie Parker, anyone is susceptible to catch Jes' Grew; anyone can be emotionally moved, and anyone can "shake that thing." A doctor attending Jes'Grew "victims" agonizes, "There are no isolated cases in this thing. It knows no class no race no consciousness. It is self-propagating and you can never tell when it will hit." 9 The large cast of characters includes PaPa LaBas (an incarnation of the African trickster, Legba), Set, Isis, and Osiris (several Egyptian gods and goddesses), the Sufi Abdul Hamid, and the Mu'tafikah (a coalition of art-nappers). A new reader of Mumbo Jumbo confronts not only a bewildering array of texts and characters but a quicksilver movement between time periods. This quicksilver movement is what I call pendulum chronology: the novel's chronological theory.

The novel's chronological theory proposes that time does not simply flow forward, like a river, but like a pendulum. To envision the immediate implications of pendulum chronology, it is necessary to enumerate a few principles.

1. If time is "a pendulum" and "Not a river," then time never moves solely in one direction; it moves back and forth. 


\section{Ethnic Studies Review Volume 26: 1}

2. "Time as a pendulum" can imply a varying range of motion. A pendulum's range of motion includes shorter sweeps, as well as longer sweeps. In pendulum chronology the sweeps include shorter reaches of time (year to year, decade to decade) as well as longer reaches of time (century to century).

3. A "jump" from one time period to the next is not abrupt movement but a sweeping motion from one part of a continuum to the next. A pendulum's path is inclusive, encompassing the time periods between each endpoint of each sweep.

4. Pendulum chronology implies a Fanonially dialectic ${ }^{10}$ pendulum. That is, it moves between not just one past and one future, but among multiple pasts, multiple presents, and multiple futures along the same continuum. The novel moves between pasts and presents and futures, syncretically taking what is relevant from each time period, generatively engaging the binaries of past and present yet refusing any easy synthesis of thesis and antithesis.

5. A pendulum is defined through motion and movement. If it stops moving, it is no longer a pendulum; thus pendulum chronology insists on constant, fluid motion among time periods. If we return to the novel's final lines, understanding the logic of pendulum chronology, the references to multiple time periods are not so puzzling; instead we can see smaller sweeps of the pendulum in the twentieth century. "Arna Bontemps was correct in his new introduction to Black Thunder. Time is a pendulum. Not a river." In the first line of this passage, Reed refers to Arna Bontemps' novel, Black Thunder (1936), the story of a slave revolt in the 1800s. The "new introduction" here is the introduction that Bontemps wrote for the 1968 re-publication of Black Thunder. Bontemps's 1968 introduction begins "Time is not a river. Time is a pendulum. The thought occurred to me first in Watts in 1934."11 Thus Reed's epilogue is Bontemps's introduction; Reed's ending is Bontemps' beginning.

Mumbo Jumbo's final lines, then, put several dates into play: the date of the novel's completion (1971), the date of the slave revolt portrayed in Black Thunder (1800), the writing and publication of Black Thunder (1936), and Bontemps' "new" introduction (1968), looking back to the production of Black Thunder (1934). Here pendulum chronology offers a fluid, but not inde- 
terminate, sense of time. It offers time as a continuum. In this case time is a coalition among several texts, texts like Black Thunder and Mumbo Jumbo, which look backwards in time to tell us about the present.

Moving backward from the novel's final lines, we can also see a pendulum sweep from the 1920s "present" of the novel back to ancient times. The central mystery, the reason why Mumbo Jumbo is a detective novel, revolves around Jes' Grew. What is it? Where did it come from? For the enemies of Jes' Grew carriers, also known as the Atonists, the question is this: how can Jes' Grew be stopped? For if everyone catches Jes'Grew, it could be "the end of Civilization as we know it."12 Near the end of the novel, PaPa LaBas is about to explain the origins of Jes' Grew, in true 1940s detective fashion. Rather than beginning his explanation from a few months earlier, in the 1920s, he traces the "crime scene" to ancient Egypt: "Well if you must know, it all began 1000 s of years ago in Egypt, according to a high up member in the Haitian aristocracy."

The next two chapters, interestingly both labeled Chapter $52,(161-191)$ proceed to explain the origins of the conflicts between the followers of Osiris (who later become people like PaPa LaBas and the Mu'tafikah) and the followers of Set (who later become Atonists, leading to the its "military arm," the Wallflower Order ${ }^{14}$ ). Throughout these two chapters, Reed's pendulum chronology is at work, drawing on references from John Milton 15 to Sigmund Freud 16 to parallel phenomena from different pasts. In the middle of this section, PaPa LaBas explains the origins of the Atonist, monotheistic, single-minded church. As LaBas describes it, the Egyptian god Set begins to create a religion of his own, moving away from the Egyptian pantheistic tradition:

If you can understand Los Angeles you can almost get the picture; imagine 2 or 3 Los Angeleses and you got Heliopolis. The legislators lay around in the Sun all day and developed a strange Body Building scene on the beach. Set decided that he would introduce a religion based upon his relationship to the Sun, and since he was a god then the Sun would also be a god. Of course this was nothing new because the Egyptians had wor- 


\section{Ethnic Studies Review Volume 26: 1}

shiped the 'heat, light, orbs, and rays' had worshiped the Sun in a pantheistic manner. With Set, the Sun's flaming disc eclipsed the rest of its parts. ${ }^{17}$

Throughout history, the followers of Osiris and Isis follow their multiply focused cosmology, the "heat, light, orb and rays." These followers maintain that their connection to multiple life forces like the loas; "feeding the loas," or honoring the many ancestral spirits, is essential to the Work of LaBas's Mumbo Jumbo Kathedral. Such connection sometimes leads to Jes' Grew outbreaks like the 1890s "flair-up"18 and the 1920s "flair-up" as the novel begins. The followers of Set, on the other hand, promote monotheistic cosmology and try to discourage all outbreaks of Jes' Grew. They worship only "the flaming disc" rather than "the rest of its parts." As Benoit Battraville, a leader in the Haitian aristocracy, explains, "There are many types of Atonists. Politically they can be 'Left,' 'Right,' 'Middle,' but they are all together on the sacredness of Western Civilization and its mission." 19 By tracing the "crime scene" back to Set's individualistic act, rather than an egalitarian act, Reed's pendulum chronology tells us that coalition cannot be created based on one individual's needs and desires.

In an early interview Reed has said that his intention in reaching far back to ancient times was to be humorous. "You're supposed to laugh when the detective goes all the way back to Egypt and works up to himself in reconstructing the crime. When he finishes the summary, everybody's asleep." 20 Yet there is also a telling wisdom in this humor. PaPa LaBas's exposition changes from crime resolution to history lesson. Such a pedagogical strategy insists on the continuity of history, arguing that events have long genealogies. It also requires an exuberant willingness to ride the sweeps of pendulum chronology.

Moving still farther back in the novel, PaPa LaBas encounters the Sufi Abdul Hamid at a "Chitterling Switch," a party to raise money for anti-lynching legislation. ${ }^{21}$ Through the 1920ssituated Hamid, Reed uses necromancy, predicting the future by using the past. Hamid prophesies:

A new generation is coming on the scene. They will use terms like 'basic' and 'really' with telling emphasis. They will extend the letter and the meaning of the word 
'bad.' They won't use your knowledge and they will call you 'sick' and 'way out' and that will be a sad day, but we must prepare for it. For on that day they will have abandoned the other world they came here with and will have become mundanists pragmatists and concretists. They will shout loudly about soul because they will have lost it. And their protests will be a shriek. A panic sound. 22

Here Reed is able to comment on his authorial "present," the artists involved with the Black Aesthetic. ${ }^{23}$ Thus, as Abdul Hamid prophesies about the "future," this anachronism triggers a recognition about the 1960s/1970s. Here, through its pendulum chronology, the novel reworks common connotations of anachronism. Other critics ${ }^{24}$ have suggested that these are two major strategies that Reed uses throughout Mumbo Jumbo: the novel's "juxtaposition" of the 1920 s and the 1960 or the anachronistic references to the 1960s during a novel ostensibly set during the 1920s. The OED definition here is "the attribution of a custom, event, etc. to a period to which it does not belong." Yet "belonging" or "wrong" periods of time signify differently in the continuum of a pendulum chronology. Anachronisms are not "wrongly" placed but deliberately placed.

In this pendulum sweep, Mumbo Jumbo challenges its readers with its pedagogy, with the way it decides to teach (or not). It requires so much context: the Harlem Renaissance, the Black Power movement of the 1960s, a working knowledge of ancient Egyptian goddesses and gods. It will not present a glossary of terms and translations or guide to intertextual references. As literary critic Sami Ludwig argues, the novel will not even present quotation marks to guide precisely who's speaking: "he said, she said." 25 In order to learn Mumbo Jumbo we must remain vigilant detectives ourselves: constantly referring back to clues, constantly inferring who is speaking, constantly working in pendulum fashion. The most it will give us is a bibliography-a partial bibliography-so that we can do some detective work, ourselves. So if we do not respect the novel's theories, it may well remain "mumbo jumbo," in the Atonist sense. If we do respect the novel's theories, it can actually lend itself to the purpose of community/coalition building: part of what PaPa LaBas and his fol- 


\section{Ethnic Studies Review Volume 26: 1}

lowers call "The Work."

Moving still farther back in the novel, my final example of pendulum chronology in Mumbo Jumbo appears in Reed's portrayal of the multiracial coalition, the Mu'tafikah. The Mu'tafikah are a group of art-nappers; they remove artifacts from museums, or what they call "Art Detention Centers." Their mission is to return these artifacts to their original nations and cultural contexts. In a footnote, Reed calls the Mu'tafikah "the bohemians of 1920s Manhattan." 26 Chapter 23 focuses on the North American branch of the Mu'tafikah, which sets up shop in a building at the edge of Chinatown. ${ }^{27}$ They are multiracial, including African Americans, Chicanos, Chinese Americans, and Whites, or, in keeping with late 1960s terminology, "Blacks, Reds, Yellows, and Whites." 28 Their leadership is collective; they rotate leaders monthly. In Chapter 23, we encounter a meeting of the Mu'tafikah, preparing for their next art-napping. A black Mu'tafikah, Herman Berbelang, reminds the Chinese American character, "Yellow Jack," of what led the Mu'tafikah to create their coalition:

You remember in that Art History class at City College.

The pact that we made that day...that we would return the plundered art to Africa, South America and China, the ritual accessories which had been stolen so that we could see the gods return and the spirits aroused. How we wanted to conjure a spiritual hurricane which would lift the debris of 2,000 years from its roots and fling it about. ${ }^{29}$

The fact that the Mu'tafikah met in an Art History class is significant: this meeting signifies on the interconnection of art and political action. Their meeting at a community college, an education designed specifically "for the people," indicates the grassroots activist component of their coalition. Moreover, the Mu'tafikah wants to play with chronology. They want to summon a "hurricane" that involves thousands of years, and "fling" that chronology around. At work in this exchange is a collective, shared memory: "You remember," says Berbelang to Yellow Jack. Such a memory carries implications for the past and for the future. Though it appears that this coalition has an end goal, the Mu'tafikah also see their coalition work as having long-term con- 
sequences over thousands of years.

This brings me to the most important aspect of pendulum chronology in Mumbo Jumbo: its implications for coalition. If "time is a pendulum," pendulum chronology means that coalition must be rethought as long-term processes, rather than as short-term relationships with finite goals. "Coalition" often connotes an alliance for a common political cause, a safe space that minimizes differences among the diverse parties involved. Like the Mu'tafikah, coalitions come together because there is something urgent that demands collective labor. However, this very urgency often forecloses the development of longer working relationships. Coalitions are typically short-lived. In an interview with cultural critic Lisa Lowe, Angela Davis calls coalitions "ephemeral."30 Davis prefers not to think about women of color activism in terms of coalition because it is a place where different agendas must be negotiated and compromised. Following Bernice Reagon's famous speech, "Coalition Politics: Turning the Century," I argue that these activities need not always be detrimental for different groups; such negotiation and compromise remain necessary for coalition work. ${ }^{31} \mathrm{~A}$ "coalition" in its original etymological sense is not a temporary, linear process that ends with a product; it is a continual process. ${ }^{32}$ Taking that intent seriously, then, I define coalition work as a place of creative and generative struggle, where differences are neither merely celebrated nor elided altogether, but worked through. Such an understanding comes from theories of coalition in women of color feminism, framed in anthologies such as This Bridge Called My Back ${ }^{33}$ and, more recently, This Bridge We Call Home. ${ }^{34}$ Rather than framing activism in terms of static "unity," or "solidarity," progressive thinkers must frame their work as Reed's Mu'tafikah have, within the dynamic, dialectical process of coalition. We must hinge our understanding of pendulum chronology in Mumbo Jumbo with our understanding of coalition-partly because the novel portrays coalition (through the Mu'tafikah) and because it is a novel that should represent our conception of the lifespan of coalition.

The importance of the Mu'tafikah's work having long-term consequences cannot be underestimated. If we take pendulum chronology as a theory, it must not only have implications for 


\section{Ethnic Studies Review Volume 26: 1}

Mumbo Jumbo; it must also have implications outside the novel. Reed's "pendulum" chronology and my application of that chronology raise several principles for progressive coalitions in the academy. Though the connection between chronology and coalition may seem tenuous at first, I suggest that Reed's novel insists on connecting "real world" politics and signifies on the history of ethnic studies coalitions through the Mu'tafikah. In the next section I offer three possible directives that pendulum chronology holds for American ethnic studies.

\section{Pendulum Chronology and American Ethnic Studies}

1. The first implication of pendulum chronology is that ethnic studies scholarship must look back to its own origins, drawing on these origins and gleaning lessons for the future.

As an example of looking "back and forth" in ethnic studies, I connect Mumbo Jumbo to the historical events of the late 1960s. Doing so means reading the recuperative work of the Mu'tafikah coalition as signifying on the work of the cultural nationalist "third world coalitions." As I indicated earlier, the novel asks us to pay close attention to the context of its own production. ${ }^{35}$ Thus we can read Mumbo Jumbo as an allegory for early ethnic studies on the West Coast; Reed completed the novel two years after the famous 1969 "Third World" strike at San Francisco State University, where students demanded the institutionalization of ethnic studies. Through Herman Berbelang, Reed describes another early imperative of institutionalized ethnic studies. "We vowed. We began to see that the Art instructor was speaking as if he didn't know we were in the room. We felt as if we were in church, stupid, dull sculpture being blown up to be religious objects." 36 Reading Berbelang's statement in context of American ethnic studies, then, we see a frustration that still brings students to ethnic studies classrooms. One of the important drives of late 1960s multiculturalism was to give students of color a sense of themselves as agents in mainstream history. ${ }^{37}$ Berbelang's frustration also points out the resistance to exoticization that also drives much of ethnic studies. That is, ethnic studies aimed to change the subject of "social studies" from an invisibly white subject to racialized ethnic subjects.

The multicultural composition of the Mu'tafikah in Reed's 
novel also recalls the multiracial group of "third world activists" in the 1960s. In Reed's own publishing career, we see a commitment to multiracial coalitions in places like Reed's own journal, the Yardbird Reader, which published a special Asian American issue in 1972. Another is the placement of two pictures: one of a 1920s African American wedding; the other, of Reed himself and other writers of color, including Asian American writer Shawn Wong. We also see a longterm commitment to coalition in Reed's collaboratively operated Before Columbus Foundation, a non-profit organization devoted to publishing multicultural works, both by white authors and authors of color. One of the photographs in the novel, in fact, portrays the original Board of Directors of the Before Columbus Foundation, most of whom remain on the Board today. ${ }^{38}$ Such multiracial coalitions helped to generate some of the central work of ethnic studies: the recuperation of forgotten or marginalized histories. This attention to recuperation is one of the debts that American ethnic studies owes the cultural nationalists such as Reed. It is a debt that remains important to remember; though cultural nationalists are currently dismissed as proponents of "identity politics," they also campaigned strongly for recuperative work. The recuperative work of ethnic studies is not finished-and in fact, this recuperative function is part of what enlivens and invigorates ethnic studies scholarship: the possibilities of rediscovering what has been forgotten.

2. The second implication of pendulum chronology for American ethnic literary studies is a holistic view of texts and scholarship, taking both "success" and "error" into account.

As I have argued, pendulum chronology operates on a Fanonian dialectic, refusing a Hegelian end to the synthesis of thesis and antithesis. Taking the Mu'tafikah chapter of Mumbo Jumbo as a case study will illustrate what I mean here. If there is a mistake that the Mu'tafikah chapter makes, it is in its gender dynamics, exemplified in the Mu'tafikah coalition. The Mu'tafikah chapter focuses on the "actions" and dialogue of the Mu'tafikah's male membership, but there is a brief mention of the "women Mu'tafikah."39 The "mistake" that I refer to here is that adding "women" as an adjective here is sexist, akin to a "lady doctor." Thus it is easy to forget that the Mu'tafikah was com- 


\section{Ethnic Studies Review Volume 26: 1}

prised of women as well as men. Such a "mistake" perhaps reflects the limited roles and choices that women of color often faced in cultural nationalist and feminist movements, 40 and remarks on how these women were often asked to choose between their race and their gender. By examining one of the novel's "errors," I employ a postpositivist realist conception of "error." This U.S.-based coalition of scholars in minority studies argue for reexamining the relationships between "personal experience, social meanings, and cultural identity"41-in academic debates. Briefly, they posit a form of knowledge-making that allows epistemologies of cultural identities to change, "based on new or relevant information." 42 As a result of this pedagogical process, literature can be both based in the context of its historical production and as theory open for revision and interpretation. Postpositivist realist theorists also place value on the room for error in intellectual inquiry. As philosopher Caroline $\mathrm{Hau}$ maintains,

Taking error seriously implies that when we reposition the issue of error and mystification within the framework of theory-mediated knowledge, we necessarily shift the debate about the status of error away from a consideration of error per se...to a consideration of the uses of error .... . Being wrong even in the most important way does not mean that one's judgment cannot in other cases be relatively reliable in referring to facts about the world. 43

For Hau teaching and learning from others involves careful dissection of their worldviews, rather absolute dismissal of a problematic epistemology-in short, the pedagogical uses of error cannot be underestimated. Insisting on the usefulness of error means that error can generate constructive action rather than invite attack. Using error also generates the possibility for literary criticism that need not be destructively antagonistic. We might see this as mistaken, but we carefully ask how it might be mistaken, leaving our own hermeneutics open for revision in the process. In short, though Mumbo Jumbo might be "wrong" in its representation of the Mu'tafikah's gender dynamics (and even this statement must be subject to careful scrutiny), this error does not mean that Mumbo Jumbo might not be reliable in other 
cases, such as Western civilization's struggle to maintain hegemony.

Pendulum chronology relies on both "failure" and "success," allowing for more balanced readings of American ethnic literatures. Thus it is only appropriate to move to the "success" of the Mu'tafikah chapter, focusing on its success in portraying coalition. Perhaps surprisingly, the Mu'tafikah, like other "third world coalitions" of the 1960s, is not a coalition based on identity politics. Though contemporary critics often accuse multiculturalism of slavish fidelity to a politics based on identity, ${ }^{44}$ the Mu'tafikah is instead, in George Lipsitz's famous words, "an identity based on politics." 45 The European branch of the Mu'tafikah includes (but is not limited to) white members. It includes women as well as men, white members as well as students of color, and crosses national boundaries. As literary critic Reginald Martin points out, "The Atonist order does not simply war against non-whites and non-Christians. It is equally intolerant of whites who will not follow the Atonist path. . . . Thor Wintergreen, a white member of the Mu'tafikah. . . . is killed by another white [because he] was audacious enough to side with those of different ethnic backgrounds." 46 For my purposes here, Reed's portrayal of coalition implies that multicultural coalitions have not always been, and are not always currently, based on essentialist identity politics. Anti-racist work here is not only for people of color.

It is also notable that the Mu'tafikah are what might now be called a transnational coalition-though during the late 1960s this would have been called "third world." In Mumbo Jumbo there are at least four branches of the Mu'tafikah: African, European, North American and South American. 47 Such a transnational connection suggests a debt that current transnational thought owes to the "third world" movement of the 1960s. That is, earlier transnational strains of the "third world" movement should be acknowledged before we discount the "third world movement" as cultural nationalists. Among critics on the Left, it is now fashionable to critique multiculturalism, without engaging the variety of practices within multiculturalism. ${ }^{48}$

Perhaps most importantly the composition and politics of Reed's multicultural Mu'tafikah suggests that there are and have 


\section{Ethnic Studies Review Volume 26: 1}

been varieties of multiculturalism. The Mu'tafikah is multiracial; it is a coalition of identity based on politics, and it is transnational. Rather than portraying coalition as a "we all get along" space, Mumbo Jumbo also pays attention to the difficulties of coalition politics, as exemplified by Fuentes, Yellow Jack, and Berbelang's fight later in the chapter. If this multicultural coalition contains elements that progressive thinkers now value, it is a variety of multiculturalism that should not be so easily dismissed now. To put it another way, I argue that blanket critiques of multiculturalism do not always serve anti-racist projects, and agree with American studies scholars such as George Lipsitz ${ }^{49}$ and Paula Moya ${ }^{50}$ who argue that such dismissals are premature. Even though sympathetic critics (such as the contributors to the important anthology Mapping Multiculturalism [1996]) offer important and incisive critiques of multiculturalism, I must respectfully offer a poststructuralist critique of the anthology's title. The editors of this anthology, by titling it Mapping Multiculturalism, posit multiculturalism as one concept and one movement, rather than presenting multiculturalism as a series of movements and practices. Yet in addition to novelists like Reed, progressive scholars such as David Palumbo-Liu have offered us other varieties of multiculturalism; Palumbo-Liu's introduction to The Ethnic Canon offers us a "critical multiculturalism," "[one that] explores the fissures, tensions, and sometimes contradictory demands of multiple cultures, rather than (only) celebrating the plurality of cultures by passing through them appreciatively." ${ }^{\prime 1}$ Though it remains to be seen if ethnic studies can accept the challenge of a critical multiculturalism, I contend that such a step is necessary before discounting multicultural discourses altogether. Going further, I would like to suggest that not all work that calls itself "multicultural" insists on such a separation of cultures. As Mumbo Jumbo also illustrates, there have been and are varieties of multiculturalism that perform this kind of work, difficult and fraught as it may be.

As one way to accept Palumbo-Liu's challenge, I offer the strategy of reading and teaching of American ethnic literatures as "dynamically multiracial." 52 I borrow this term from Ronald Takaki, who presciently coined it in the preface to his multiracial study Iron Cages (1976): 
Like many other scholars, I had parceled out white attitudes toward different racial groups almost as if there were no important similarities as well as differences in the ways whites imaged and treated them. Yet I knew that the reality of white America's experience was dynamically multiracial. 53

Takaki is referring to the dangerous tunnel vision of ethnic studies scholarship: the tendency to remain within one racialized cubicle of study. Here I expand the scope of Takaki's term: it is not solely white America's experience that is "dynamically multiracial," but all of America's experience. Takaki's explorations of "similarities as well as differences" indirectly provides useful groundwork for cultural historian Vijay Prashad's later interracial study, Everybody was Kung-Fu Fighting: Afro-Asian Connections and the Myth of Cultural Purity (2001). In Prashad's important study, he rejects the term "multiculturalism" in favor of historian Robin Kelley's "polyculturalism."54 Central to Prashad's critique of multiculturalism is the fixed and separate nature of cultures inherent in multicultural paradigms. Yet Prashad's own Preface echoes, perhaps unconsciously, Takaki's mission/mandate: "The task of the historian is not to carve out the lineages but to make sense of how people live culturally dynamic lives." 55 What is remarkable about both historians' studies is their dynamic sense of multiracial imbrication. Reading Takaki and Prashad together, as I have done briefly here, offers one model of dialectic scholarship based on pendulum chronology. Looking back to past scholarship and ahead to current scholarship, I am able to suggest directions for future scholarship.

Like Takaki and Prashad, I argue that we should teach racialization interracially: that is, teach race as interdependently and multidirectionally formed, which varies over time. In short, ethnic studies scholarship such as recent studies of African/Asian connections is moving towards a comparative model; this move to the comparative has its roots in earlier "multicultural" scholarship,56 emphasizing that the pendulum can also swing between histories of racialized minorities. Reading Mumbo Jumbo in terms of pendulum chronology reminds us of the intertwined histories of Whites and people of color; it is not relevant solely for African American studies, but American studies and 


\section{Ethnic Studies Review Volume 26: 1}

American ethnic studies as well. By broadening the relevant scope of Mumbo Jumbo, I do not intend to suggest that the novel should not be studied within the context of African American studies. Rather, I suggest that the novel's sections on the Mu'tafikah might be taught as part of an Asian American studies course, for example. This is one way that we might read various racializations (including Blackness, Whiteness, Asian-ness, for example) and their imbrications. 57

3. Pendulum chronology includes the travel of literature. Scholars of American ethnic literature must remember that without action, there is no pendulum.

Literature travels between what is and what might be, and in that traversal it sometimes makes mistakes, giving us time and space to realize that we make mistakes. A pendulum does not and should not rest because, as Reed's novel points up, "What goes around will come around." Thus scholars of American ethnic studies must talk to each other and to others who do identity-based work in the academy, such as scholars in women/gender studies. Under an anti-affirmative action White House administration, it is abundantly clear to progressive thinkers that multiracial coalitions matter, or, as George Lipsitz puts it, "interethnic anti-racism" matters. 58 During this administration's "War on Terror," the term "coalition" has come to signify a group of nations at war. "Coalition" also has deep significance for progressive grassroots organizations. Literature theorizes multiracial coalition by describing it, representing it, but also by taking fictional license and signifying on what multiracial coalition might be. As an example, though much of the current scholarship on Afro-Asian connections is historical, scholars seeking coalition must marshal all the resources possible in order to do coalition work.

"Part of the racial problem today," Lipsitz argues, "is a knowledge problem." 59 Some of this urgent coalition work can and must take place in the classroom. Scholars of American ethnic studies must look multidirectionally, using not only past models of coalition but theorizing future models of coalition. As Reed's novel shows us, we must look backward and forward to understand how coalitions have worked and can work, understanding that we need not reinvent the wheel of coalition work 
every time the need for coalition arises. We must use as many lenses for coalition as we can: using not only historical but literary models of coalition. As books like Mumbo Jumbo and historians like Gary Okihiro propose, 60 multiracial coalitions have existed, and probably for longer than we know. If, as Mumbo Jumbo contends, "Time is a pendulum" and "Not a river," those who work in the coalitions of American ethnic studies must be aware of the pendulum-like motions such as politics, rather than a unidirectional motion. The danger for us, as for the pendulum, is inaction.

The political pendulum insists that we need broader ways to think about and to work in multiracial coalitions. Scholars of American ethnic studies must, in Jacqui Alexander's words, "become fluent in each other's stories." 61

\section{Acknowledgements}

I would like to thank the members of my writing group-Kimberly Emmons, Brandy Parris, and Brooke Stafford-who constantly remind me of the pleasures of writing in community. Dr. Johnnella Butler's generous mentoring has sustained me throughout my graduate career. Special thanks to my family, especially Helen Nimura, Teruko Nimura, and Josh Parmenter, for abundant love and support.

\section{NOTES}

1 Ishmael Reed, Mumbo Jumbo (New York: Scribner, 1972), 218, original italics.

2 Ibid., 218. For an extended reading of the italicized final lines, see Shadle (26). While Shadle emphasizes the screenplay aspect of these lines, I take them as another aspect of the novel's play with chronology.

3 Ibid., 218.

4 Theodore O. Mason. "Performance, History, and Myth: The Problem of Ishmael Reed's Mumbo Jumbo." Modern Fiction Studies 34, no.1 (1988): 100

5 Henry Louis Gates, Jr. "'the Blackness of Blackness": A Critique of the Sign and the Signifying Monkey." In Studies in Black American Literature, ed. Joe WeisImann et al. (Greenwood, FL: Penkevill), 1984, 163 , orig. italics.

6 Ishmael Reed, interview by [NAME], in Conversations with Ishmael Reed, eds. Bruce Dick and Amritjit Singh, (Jackson: University of 
Ethnic Studies Review Volume 26: 1

Mississippi Press, 1995), 60.

7 For an extended typology of Mumbo Jumbo as detective novel, see Gates' treatment (161-64).

8 Jes' Grew is named after Harriet Beecher Stowe's character Topsy. Topsy is, of course, an enslaved Black orphan who does not know who her parents are; when asked about her origins, she replies that she "jes'grew." With this intertextual reference, Reed moves us back to Uncle Tom's Cabin (1852), in keeping with the novel's multiple chronologies.

9 Reed, Mumbo, 5.

10 I take this concept from Lou Turner's article. Through Turner's account, my understanding of a Fanonian dialectic, as opposed to a Hegelian dialectic, is that a Fanonian dialectic is constantly open for revision; it does not rest with a final synthesis.

11 Arna Bontemps, "Introduction." Black Thunder (New York: Beacon Press, 1968), vii.

12 Reed, Mumbo, 4. For the Atonist doctor, Civilization "as we know it" can only be Western civilization.

13 Ibid., 160.

14 Ibid., 132.

15 Ibid., 171.

16 Ibid., 172.

17 Ibid, 173.

18 Ibid, 4.

19 Ibid, 136.

20 Reed, Ishmael Reed interview, 15-16.

21 Ibid, 27.

22 Ibid, 39.

23 According to the Oxford English Dictionary, "nitty gritty" made its first appearance in print around 1963.

24 Gates characterizes this narrative mode as "discontinuous and frag- 


\section{Nimura-Time is Not a River}

mentary" (169).

25 Sami Ludwig, "Ishmael Reed's Inductive Narratology of Detection," African American Review 32, no.3 (1998): 435.

26 Reed, Mumbo, 15.

27 Ibid., 82.

28 Ibid., 83.

29 Ibid., 87-88.

30 Angela Davis, interview with Lisa Lowe. "Angela Davis: Reflections on Race, Class, and Gender in the USA. In The Politics of Culture in the Shadow of Capital, ed. Lisa Lowe and David Lloyd. Durham, NC: Duke University Press, 1997: 316.

31 Berenice Johnson Reagon, "Coalition Politics; Turning the Century."In Home Girls: A Black Feminist Anthology, ed. Barbara Smith. Latham, NY: Kitchen Table, Women of Color Press, 1983.

32 According to the Oxford Dictionary of American English, the Latin root of the verb "coalesce" is coalescere, which means "to grow together."

33 Gloria Anzaldúa and Cherríe Moraga, eds. This Bridge Called My Back: Radical Writings by Women of Color. Latham, NY: Kitchen Table: Women of Color Press, 1981.

34 Gloria Anzaldúa and AnaLouise Keating, eds. This Bridge We Call Home. New York: Routledge, 2002.

35 Reed submitted Mumbo Jumbo to the publisher on January 31, 1971 (Interview 62).

36 Reed, Mumbo, 89.

37 Director Spike Lee highlights this frustration in Do the Right Thing (1989). "Why are there no [Black] brothers on the wall?" an African American character, Moochie, asks the white neighborhood pizzeria owner." The issue here is about representation in Pizza Man's cosmology: not a simplistic matter of token inclusion, but recognition that noteworthy American figures exist outside of White America.

38 Shawn Wong, personal communication with author, Seattle, Washington, 5 May 2003. 


\section{Ethnic Studies Review Volume 26: 1}

39 Reed, Mumbo, 82.

40 See Aída Hurtado's study for more discussion of women's roles in the Chicano and Black Power movements. By characterizing the cultural nationalist movements in this fashion, I do not mean to discount the efforts of women who were able to play important roles in these movements, such as Fannie Lou Hamer and Angela Davis.

41 Paula Moya. "Introduction." Reclaiming Identity: Realist Theory and the Predicament of Postmodernism. Berkeley: University of California Press, 2000: 30 .

42 Ibid., 13.

43 Caroline Hau. "On Representing Others: Intellectuals, Pedagogy, and the Uses of Error." In Moya and Hames-Garcia 160.

44 For an excellent summary of other leftist critiques of multiculturalism, see Avery Gordon and Christopher Newfield's introduction to Mapping Multiculturalism. I do not mean to discount this anthology completely; it takes the implications of multiculturalism seriously, weighing both its advantages as well as its disadvantages.

45 George Lipsitz "to tell the Truth and Not Get Trapped: Why Interethnic Antiracism Matters Now." In Orientations: Mapping Studies in the Asian Diaspora, eds. Kandace Chuh and Karen Shimakawa, Durham, NC: Duke University Press, 2001: 296.

46 Reginald Martin. "Hoodoo as Literary Method: Ishmael Reed's 'True Afro-American Aesthetic." In Ishmael Reed and the New Black Aesthetic Critics. New York: St. Martin's Press, 1988: 87.

47 Reed, Mumbo, 84.

48 See, for example, E. San Juan, Jr.'s recent study Racism and Cultural Studies.

49 Lipsitz 308-9.

50 Moya, Learning, 130

51 David Palumbo-Liu. "Introduction." In The Ethnic Canon: Histories, Institutions, and Interventions. Minneapolis: University of Minnesota Press, 1995: 5.

52 Grace Hong's groundbreaking essay on transracial solidarity in Hisaye Yamamoto's short stories is a good example of such a reading. 
53 Ronald Takaki. Iron Cages: Race and Culture in the 19th Century. Oxford: Oxford University Press, 1990. Reprint with new epilogue: vi.

54 Vijay Prashad. Everybody was Kung-Fu Fighting: Afro-Asian Connections and the Myth of Cultural Purity. Boston: Beacon Press, 2001: xi-xii.

55 Ibid., xii.

See Johnnella Butler's model of "American ethnic studies as matrix" in Color Line to Borderlands as a potential model which echoes my emphasis on comparative work.

56 In my introductory course on Asian American literature, I have devoted a unit to African American characters in two novels: Ruth Ozeki's My Year of Meats (1997) and Chang-Rae Lee's Native Speaker (1995).

57 Lipsitz, 296. Following this imperative, scholars in Asian American Studies, for example, have turned to a multiracially comparative Asian American Studies. Several historians are tracing genealogies of AfroAsian coalitions. A few examples include Gary Okihiro's Margins and Mainstreams; Vijay Prashad's Everybody Was Kung-fu Fighting; Moonho Jung's forthcoming work on coolie labor and slave labor in the American South and Caribbean; and the Journal of Asian American Studies, which recently published a special issue last year on African American/Asian American cross-identification.

59 Lipsitz, 308.

60 See Okihiro, Margins and Mainstreams, Chapter 2, "Is Yellow Black or White?"

61 Lowe, 317. 